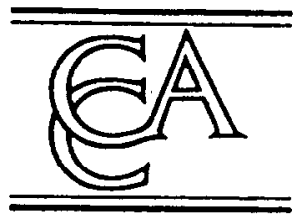

\title{
Comparison of N-terminal pro-atrial natriuretic peptide and atrial natriuretic peptide in human plasma as measured with commercially available radioimmunoassay kits
}

\author{
Frans Boomsma*, Usha M. Bhaggoe, Arie J. Man in 't Veld, \\ Maarten A.D.H. Schalekamp \\ Cardiovascular Research Institute COEUR, Division of Internal Medicine I, University Hospital \\ Dijkzigt/Erasmus University, Dr. Molewaterplein 40, 3015 GD Rotterdam, The Netherlands
}

Received 10 October 1995; revised 5 February 1996; accepted 11 February 1996

\begin{abstract}
Atrial natriuretic peptide (ANP) has become an important parameter for assessing the condition of patients with cardiac disease. Recently, attention has also focused on $N$-terminal pro-atrial natriuretic peptide (NtproANP) in this context. NtproANP circulates in plasma in higher concentration, is more stable ex vivo, and may be a better parameter for cardiac function over time. We have evaluated a new commercially available radioimmunoassay kit for NtproANP and compared results and method with those of ANP measurements. The NtproANP kit was found to be reliable and easy to use (no plasma extraction step is necessary), with good reproducibility (coefficients of variation $7-15 \%$ ). Normal values in 15 healthy laboratory workers, 25 healthy elderly subjects and 25 patients with heart failure were $207 \pm 70,368 \pm 134$ and $1206 \pm 860 \mathrm{pmol} / \mathrm{l}$, respectively, 8.3, 11.8 and 13.0 times higher, respectively, than corresponding ANP concentrations. NtproANP correlated well with ANP $(r 0.64-0.78)$. We conclude that plasma NtproANP measurement may be a good alternative to plasma ANP measurement: technically, it is easier to perform, and NtproANP is more stable in plasma. Whether NtproANP is a better diagnostic and prognostic parameter than ANP remains to be further established.
\end{abstract}

Keywords: N-Terminal pro-atrial natriuretic peptide; Atrial natriuretic peptide; Radioimmunoassay; Human plasma

${ }^{*}$ Corresponding author, Tel.: + 31104633764 ; Fax: + 31104634531.

0098-8981/96/\$15.00 ( 1996 Elsevier Science B.V. All rights reserved PII S0009-8981(96)06311-5 


\section{Introduction}

The measurement in plasma of atrial natriuretic peptide (ANP), first discovered in 1981 [1], has become an important parameter for assessing the condition of patients with cardiac disease, and indeed, for identifying patients at risk of heart failure [2-5]. ANP is a 3-kDa peptide which is split off from the C-terminus of a 126-amino acid prohormone mainly released from heart atria upon stretching. The remaining 98-amino acid fragment, named $N$-terminal pro-ANP (NtproANP), has no biological activity, contrary to ANP itself. Although NtproANP is produced in equimolar amounts, it circulates in plasma, due to its much lower clearance rate, in much higher concentrations than ANP [6-9]. NtproANP is also reported to be more stable ex vivo [10,11]. In recent years, therefore, attention has also focused on measurement of plasma NtproANP concentration as an alternative to ANP, especially since NtproANP can be determined directly in plasma without the prior extraction necessary for ANP measurements. Some reports have concluded that NtproANP may be a better marker for cardiac dysfunction and prognosis than ANP [12-14].

We have evaluated a radioimmunoassay kit for human plasma NtproANP which recently became available commercially and compared the NtproANP values measured in plasmas of 15 healthy laboratory workers, 25 healthy elderly volunteers and 25 patients with congestive heart failure, with ANP values measured in the same samples.

\section{Materials}

\subsection{Plasma}

Blood was obtained from subjects and patients who had been in the supine position for at least 30 min after insertion of a catheter into an antecubital vein. Blood was collected in polystyrene tubes containing EDTA and aprotinin (1.9 $\mathrm{mg}$ and $100 \mathrm{kIU} / \mathrm{ml}$ blood, respectively). The tubes were centrifuged within $15 \mathrm{~min}\left(4^{\circ} \mathrm{C}, 10 \mathrm{~min}, 3000 \times g\right)$ and the plasma was separated and stored in polyethylene tubes at $-80^{\circ} \mathrm{C}$ until assayed. For some special purposes, blood was collected in heparinized tubes with or without glutathione $(1.2 \mathrm{mg} / \mathrm{ml} \mathrm{blood})$ and in tubes containing EDTA $(1.9 \mathrm{mg} / \mathrm{ml}$ blood) or trisodium citrate $(3.4 \mathrm{mg} / \mathrm{ml}$ blood).

\subsection{NtproANP assay}

NtproANP concentrations in plasma were determined with a commercial kit from Biotop, Oulu, Finland. This 100-tube kit contains an assay 
buffer (sodium phosphate), standards $(0,30,100,300,1000$ and 3000 pmol/l), anti-NtproANP produced in rabbits, ${ }^{125} \mathrm{I}$-NtproANP $(<1 \mu \mathrm{Ci})$, sheep antiserum against rabbit gammaglobulin in polyethylene glycol as a precipitation agent, and a control sample.

\subsection{ANP assay}

ANP concentrations in plasma were determined with a commercial kit from Nichols Institute, Wijchen, The Netherlands. The procedure and characteristics of this method, which involves extraction from plasma using C-18 SepPak cartridges followed by radioimmunoassay, have been described previously $[15,16]$.

\subsection{Statistics}

Data are reported as means \pm S.D., unless otherwise indicated. For comparison of paired observations Student's $t$-test and Mann-Whitney's $U$-test were used. $P$ values $<0.05$ were considered significant.

\section{Methods}

\subsection{Procedure for NtproANP determination}

Into $12 \times 75 \mathrm{~mm}$ polystyrene tubes were pipetted $25 \mu \mathrm{l}$ standard, control or plasma sample followed by $200 \mu \mathrm{l}$ NtproANP antiserum (zero-standard and bidistilled water, respectively, for non-specific binding determination). After addition of $200 \mu \mathrm{l}^{125} \mathrm{I}$-NtproANP, reconstituted in assay buffer, the tubes were vortex-mixed and incubated at $+4^{\circ} \mathrm{C}$ for 22 h. Next, $0.5 \mathrm{ml}$ sheep anti-rabbit gammaglobulin in aqueous polyethylene glycol was added (not to the tubes for total counts determination). The tubes were mixed, incubated for $30 \mathrm{~min}$ at room temperature, and centrifuged $\left(15 \mathrm{~min},+4^{\circ} \mathrm{C}, 2500 \times g\right)$. The supernatant was aspirated (except for the tubes for total counts determination) and the radioactivity was counted for $2 \mathrm{~min}$ in a RIASTAR 5420 gamma counter (Packard, Meriden, CT). A spline curve-fitting program was used to construct a standard curve and determine concentrations of NtproANP in the samples.

\section{Results}

The procedure as given by the manufacturer worked well. In 16 consecutive assays the binding was $35.2 \pm 3.4 \%$ and the non-specific binding $1.3 \pm 0.4 \%$. The ED20, ED50 and ED80 were $1520 \pm 264$, $419 \pm 61$ and $111 \pm 16 \mathrm{pmol} / \mathrm{l}$, respectively, while the inflection point was at a concentration of $436 \pm 91 \mathrm{pmol} / 1$. All determinations were carried out 
in duplicate; average variation between duplicate measurements in a typical assay was $3.4 \pm 3.0 \%$. In all but one of the 16 assays the computer program needed only one iteration and no smoothing factor for constructing the standard curve. A representative standard curve is depicted in Fig. 1.

A control sample provided with the kit (stated to contain $180 \mathrm{pmol} / \mathrm{l}$ ) and a plasma pool (from patients with hypertension and with heart failure) were included in all assays at the beginning, in the middle and at the end of the assay series. Average interassay values were 194 (CV 9.3\%) pmol/1

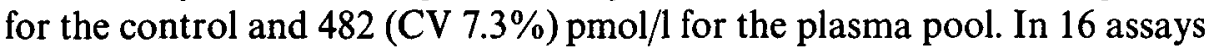
the average values found for the control sample at the beginning, the middle and the end of the assay were 179 (CV 6.8\%), 197 (CV 14.5\%) and $206(\mathrm{CV} 12.4 \%) \mathrm{pmol} / \mathrm{l}$, respectively. The corresponding values for the plasma pool were 463 (CV 8.2\%), 481 (CV 6.8\%) and 503 (CV 11.4\%) $\mathrm{pmol} / \mathrm{l}$, respectively. The differences in measured values of both the control sample and the plasma pool at the beginning, the middle and the end of the assay were statistically significant (repeated measures ANOVA).

In order to investigate whether plasmas obtained with different anticoagulation methods give identical results, we measured NtproANP in heparinized plasma with and without glutathione, EDTA plasma with and

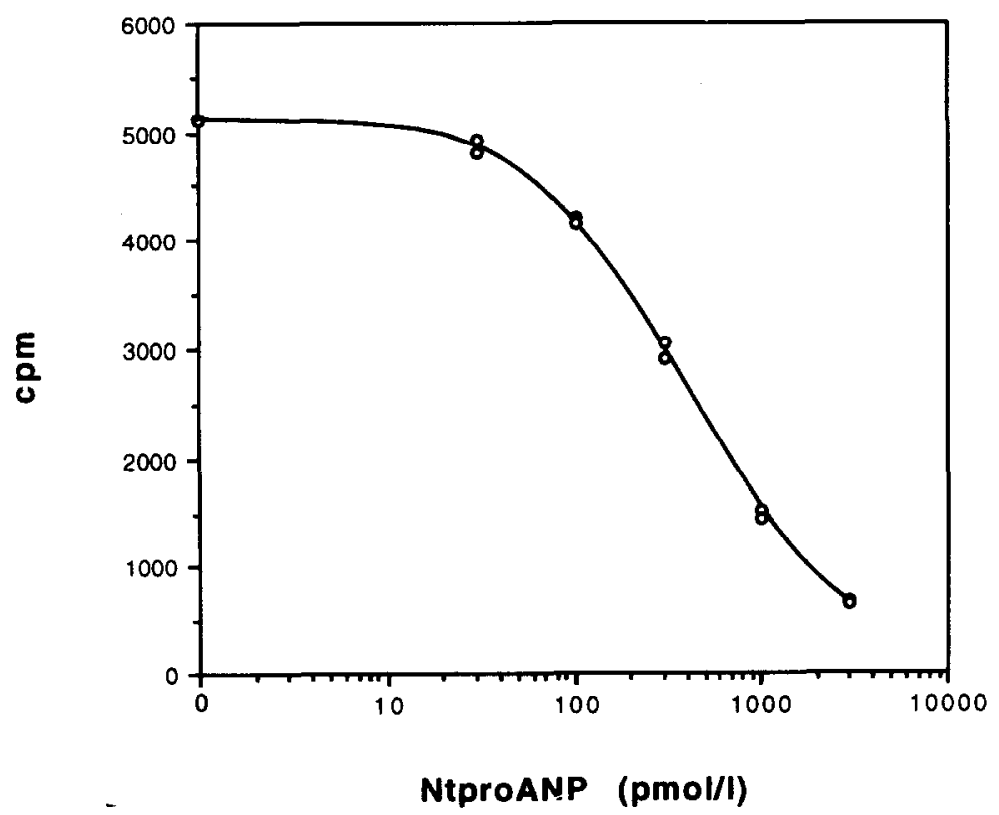

Fig. 1. Representative standard curve from the NtproANP radioimmunoassay. 
without aprotinin, and citrated plasma prepared from blood obtained from 8 healthy volunteers. EDTA plasma with and without aprotinin gave similar results ( $208 \pm 81$ and $204 \pm 86 \mathrm{pmol} / \mathrm{l}$, respectively), heparinized plasma gave considerably higher NtproANP values, but similar with and without glutathione ( $396 \pm 119$ and $371 \pm 120 \mathrm{pmol} / \mathrm{l}$, respectively), while citrated plasma gave intermediate values $(309 \pm 84 \mathrm{pmol} / \mathrm{l})$.

The assay is valid in the range $30-3000 \mathrm{pmol} / \mathrm{l}$. The lower limit of 30 $\mathrm{pmol} / \mathrm{l}$ is amply sufficient for normal plasmas. In plasmas of patients with severe heart failure (NYHA class III/IV) NtproANP concentrations occasionally exceeded the upper standard level of $3000 \mathrm{pmol} / 1$. In $17 \mathrm{such}$ cases, with NtproANP concentrations of $3322 \pm 212 \mathrm{pmol} / 1$ calculated from the undiluted samples, the determinations were repeated with 10-fold diluted samples. Results were then higher, but not exceedingly so $(3480 \pm 744 \mathrm{pmol} / \mathrm{l})$.

Plasma NtproANP concentrations found in healthy laboratory workers, healthy elderly subjects without overt signs of heart problems and in patients with congestive heart failure (age- and sex-matched with the healthy elderly subjects) are reported in Table 1 . Also reported here are the corresponding plasma ANP concentrations and the NtproANP/

Table 1

Data of the three groups of subjects

\begin{tabular}{llll}
\hline & $\begin{array}{l}\text { Healthy laboratory } \\
\text { workers }\end{array}$ & $\begin{array}{l}\text { Healthy elderly } \\
\text { subjects }\end{array}$ & $\begin{array}{l}\text { Patients with } \\
\text { congestive heart } \\
\text { failure }\end{array}$ \\
\hline$n$ & 15 & 25 & 25 \\
Age (years) & $32 \pm 8$ & $63 \pm 4$ & $63 \pm 3$ \\
Females/males & $8 / 7$ & $15 / 10$ & $15 / 10$ \\
NtproANP (pmol/1) & & $368 \pm 134$ & $1206 \pm 860$ \\
Mean \pm S.D. & $207 \pm 70$ & 335 & 961 \\
Median & 210 & $312-423$ & $851-1561$ \\
CI & $168-245$ & $31 \pm 12$ & $111 \pm 97$ \\
ANP (pmol/l) & & 28 & 76 \\
Mean \pm S.D. & $26 \pm 9$ & $27-36$ & $71-151$ \\
Median & 27 & & $12.1 \pm 4.9$ \\
CI & $20-31$ & $12.2 \pm 3.6$ & 13.0 \\
NtproANP/ANP ratio & & 11.8 & $10.1-14.1$ \\
Mean \pm S.D. & $8.5 \pm 2.2$ & $10.7-13.7$ & \\
Median & 8.3 & & \\
CI & $7.3-9.7$ & & \\
\hline
\end{tabular}

$\mathrm{CI}, 95 \%$ confidence interval. 
ANP ratios. Comparison of the two healthy groups showed that NtproANP and the NtproANP/ANP ratio were higher in the elderly group than in the (younger) laboratory workers, while ANP concentrations were not significantly different. The heart failure group had higher NtproANP and ANP concentrations, while the NtproANP/ANP ratio was not different from the ratio of the elderly subjects, but higher than that of the laboratory workers. In all three groups NtproANP levels correlated strongly with ANP levels ( $\mathrm{r} 0.64-0.69$ ); in the overall group of 65 samples the correlation coefficient was 0.78 (Fig. 2), with a regression line of: $(\mathrm{pmol} / 1 \mathrm{NtproANP})=7.5 \times(\mathrm{pmol} / 1 \mathrm{ANP})+195$.

In 8 strongly haemolytic plasmas of subjects without cardiac disease normal NtproANP concentrations were found $(232 \pm 41 \mathrm{pmol} / \mathrm{l})$, while ANP measurements in these samples were unsuccessful.

\section{Discussion}

The NtproANP kit proved to be a reliable and simple method for determining NtproANP levels in plasma, with good reproducibility. A slight end-of-assay effect was, however, consistently present. The values found in healthy subjects are in agreement with those reported by the manufacturer. Mean values reported in the literature, with the use of different assay and standardization methods, mostly vary between 160 and $588 \mathrm{pmol} / 1[6-8,12-14,17-19]$, but Lerman et al. report a much lower

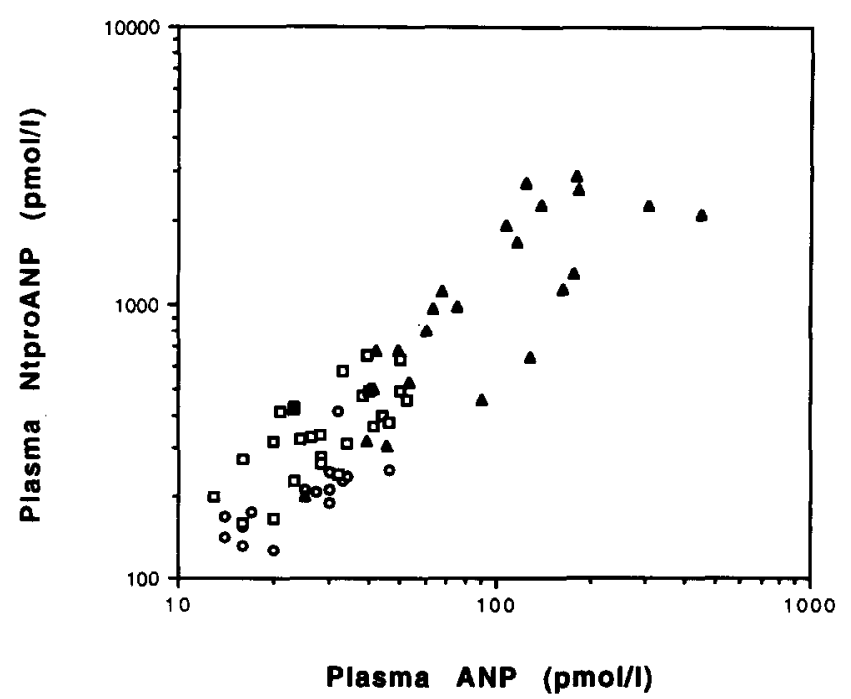

Fig. 2. Correlation between plasma ANP and plasma NtproANP. 
value of $28 \mathrm{pmol} / 1$ [12]. The values we found in elderly subjects were higher than those of younger laboratory workers. This difference suggests that NtproANP levels increase with age, as has also been reported by Hall et al. [14]. As the kidney plays an important role in the metabolism of NtproANP [7], it can, however, not be excluded that reduced renal function in the elderly is responsible for the higher NtproANP concentrations. In agreement with previous reports, NtproANP levels in patients with congestive heart failure are markedly elevated compared to healthy, age- and sex-matched subjects.

The NtproANP/ANP ratio is not different in the two elderly groups, but is lower in the younger group. This is due to the lower NtproANP levels in this group, while ANP levels are not different from those in the healthy elderly subjects. In the heart failure patients both NtproANP and ANP are about 3-fold higher than in the healthy elderly subjects, and thus the ratios are not different. Comparison with literature values is fraught with difficulties, as ANP levels vary considerably between laboratories and assay methods, much more so than NtproANP levels. It is interesting to note that Itoh et al. [7] found a ratio of 17.4 in normal controls, but a lower ratio of 9.0 in patients with heart failure.

ANP and NtproANP concentrations were highly correlated, in agreement with most literature reports $[7,9,17,20]$. Some authors however found a lower correlation coefficient of $0.4-0.5[13,14]$ while Lerman et al. [12] found no correlation at all. Release of the atrial natriuretic prohormone leads to equimolar amounts of NtproANP and ANP, but due to the rnuch more rapid clearing of ANP from the circulation NtproANP circulates in plasma in much higher concentrations. Under stable conditions a good correlation between NtproANP and ANP concentrations might be expected. In situations where ANP levels fluctuate rapidly, NtproANP levels remain much more stable $[8,13]$, and in such instances the correlation between the two may become less significant. The same reasoning may of course explain differences in NtproANP/ANP ratios.

We conclude that the described kit for plasma NtproANP measurement is a reliable method, which offers several advantages compared to measurement of plasma ANP concentration. Technically, the higher NtproANP levels and the lack of nccessity for a plasma extraction step make the NtproANP measurement easier and less time-consuming to perform. In strongly haemolytic blood samples normal NtproANP levels were found, while ANP measurements can not be made in such samples. Contrary to ANP measurements, measurements of NtproANP rarely fall off the standard curve, and if they do, the curve seems to be quite robust in this respect. NtproANP is much more stable than ANP, even though the latter is not as unstable as has sometimes been suggested [16]; the fact 
that NtproANP, however, is stable for 3 days at room temperature is a great advantage $[10,11]$. From a diagnostic point of view, the much longer half-life of NtproANP suggests that it may be a better indicator for heart function over time than the short-lived ANP, as has recently been reported $[13,14]$. Only in situations where an indication of rapid changes in heart function are of interest would ANP measurement be more advantageous.

Although from both a practical as well as a theoretical point of view measurement of NtproANP seems to be an attractive alternative to measurement of ANP, it should first be firmly established that NtproANP is at least as good a diagnostic and prognostic parameter as ANP. Further studies on the prognostic power of measurements of ANP, NtproANP and other neurohormonal parameters on the outcome of cardiac diseases are needed therefore before a definitive recommendation for any of these parameters can be made.

\section{References}

[1] deBold A, Borenstein H, Veress A, Sonnenberg $H$. A rapid and potent natriuretic response to intravenous injection of atrial myocardial extract in rat. Life Sci 1981;28:89-94.

[2] Tikkanen J, Fyhrquist F, Metsarinne K, Leidenius R. Plasma atrial natriuretic peptide in cardiac disease and during infusion in healthy subjects. Lancet 1985;ii:6669.

[3] Nakaoka H, Imitaka K, Amano M, Fujii J, Ishibashi M, Yamaji T. Plasma levels of atrial natriuretic factor in patients with congestive heart failure. $N$ Engl $J$ Med 1985;313:892-893.

[4] Francis GS, Benedict C, Johnstone DE et al. Comparison of neuroendocrine activation in patients with left-ventricular dysfunction with and without congestive heart failure. Circulation 1990;82:1724-1729.

[5] Davis KM, Fish LC, Elahi D, Clark BA, Minaker KL. Atrial natriuretic peptide levels in the prediction of congestive heart failure risk in frail elderly. J Am Med Assoc 1992;267:2625-2629.

[6] Sundsfjord JA, Thibault G, Larochelle P, Cantin M. Identification and plasma concentrations of the $\mathrm{N}$-terminal fragment of proatrial natriuretic factor in man. $\mathrm{J}$ Clin Endocrinol Metab 1988;66:605-610.

[7] Itoh H, Nakao K, Sugawara A, Saito Y, Mukoyama M, Morii N, Yamada T, Shiono $\mathrm{S}$, Arai $\mathrm{H}$, Hosoda $\mathrm{K}$, Imura $\mathrm{H}$. $\gamma$-Atrial natriuretic polypeptide $(\gamma \mathrm{ANP})$-derived peptides in human plasma: cosecretion of N-terminal $\gamma \mathrm{ANP}$ fragment and $\alpha \mathrm{ANP}$. J Clin Endocrinol Metab 1988;67:429-437.

[8] Buckley MG, Sagnella GA, Markandu ND, Singer DRJ, MacGregor GA. Concentrations of $\mathrm{N}$-terminal proANP in human plasma: evidence for proANP(1-98) as the circulating form. Clin Chim Acta 1990;191:1-14.

[9] Mathisen P, Hall C, Simonsen S. Comparative study of atrial peptides ANF(1-98) and $\operatorname{ANF}(99-126)$ as diagnostic markers of atrial distension in patients with cardiac disease. Scand J Clin Invest 1993;53:41-49. 
[10] Hall C, Aaberge L, Stokke O. In vitro stability of N-terminal proatrial natriuretic factor in unfrozen samples: an important prerequisite for its use as a biochemical parameter of atrial pressure in clinical routine. Circulation 1995;91:911.

[11] Davidson NC, Coutie WJ, Struthers AD. N-Terminal proatrial natriuretic peptide and brain natriuretic peptide are stable for up to $6 \mathrm{~h}$ in whole blood in vitro. Circulation 1995;91:1276.

[12] Lerman A, Gibbons RJ, Rodeheffer RJ, Bailey KR, McKinley LJ, Heublein DM, Burnett JC. Circulating N-terminal atrial natriuretic peptide as a marker for symptomless left-ventricular dysfunction. Lancet 1993;341:1105-1109.

[13] Kettunen RVJ, Leppäluoto J, Jounela A, Vuolteenaho O. Plasma N-terminal atrial natriuretic peptide in acute myocardial infarction. Am Heart J 1994;127:1449-1455.

[14] Hall C, Rouleau JL, Moyé L, de Champlain J, Bichet D, Klein M, Sussex B, Packer M, Rouleau J, Arnold MO, Lamas GA, Sestier F, Gottlieb SS, Wun C-C, Pfeffer M. $\mathrm{N}$-Terminal proatrial natriuretic factor; an independent predictor of long-term prognosis after myocardial infarction. Circulation 1994;89:1934-1942.

[15] Rosmalen FMA, Tan ACITL, Tan HS, Benraad TJ. A sensitive radioimmunoassay of atrial natriuretic peptide in human plasma, using a tracer with an immobilized glycouril agent. Clin Chim Acta 1987;165:331-340.

[16] Bhaggoe UM, Boomsma F, Admiraal PJJ, Man in 't Veld AJ, Schalekamp MADH. Stability of human plasma atrial natriuretic peptide during storage at $-80^{\circ} \mathrm{C}$. Clin Chim Acta 1993;223:179-184.

[17] Meleagros L, Gibbs JSR, Ghatei MA, Bloom SR. Increase in plasma concentrations of cardiodilatin (amino terminal pro-atrial natriuretic peptide) in cardiac failure and during recumbency. Br Heart $\mathbf{J}$ 1988;60:39-44.

[18] Winters CJ, Sallman AL, Baker BJ, Meadows J, Rico DM, Vesely DL. The $\mathrm{N}$-terminus and a $4000-\mathrm{MW}$ peptide from the midportion of the $\mathrm{N}$-terminus of the atrial natriuretic factor prohormone each circulate in humans and increase in congestive heart failure. Circulation 1989;80:438-449.

[19] Vuolteenaho O, Koistinen P, Martikkala V, Takala T, Leppäluoto J. Effect of physical exercise in hypobaric conditions on atrial natriuretic peptide secretion. Am J Fhysiol 1992;263:R647-R652.

[20] Buckley MG, Markandu ND, Sagnella GA, MacGregor GA. N-Terminal atrial natriuretic peptide and atrial natriuretic peptide in human plasma: investigation of plasma levels and molecular circulating form(s) using radioimmunoassays for proatrial natriuretic peptide (31-67), pro-atrial natriuretic peptide (1-30) and atrial natriuretic peptide (99-126). Clin Sci 1994:87:311-317. 